Revista de Antropología Social

ISSN: 1131-558X

http://dx.doi.org10.5209/RASO 53980

\title{
Formas reales de dominación
}

Salvador Maldonado Aranda ${ }^{1}$

AGUDO SANCHÍZ, Alejandro y ESTRADA SAAVEDRA, Marco (Coord.). 2014. Formas reales de la dominación del Estado. Perspectivas interdisciplinarias del poder y la política. México, D.F.: El Colegio de México.

Pocos libros crean márgenes conceptuales en el mundo de los debates académicos sobre el Estado, y Formas reales de la dominación del Estado es, sin duda, uno de ellos. Desde el propio título, cuya frase fue acuñada por grandes teóricos como Corrigan, Ramsay y Sayer (1980: 17) para dar cuenta de la "materialidad" del Estado en la vida de la gente, se deja entrever la profunda preocupación subyacente en el libro por las formas de dominación y legitimación en espacios insulares donde supuestamente el Estado no existe o es fallido. Resulta importante, por tanto, ubicar cuáles son esas preocupaciones que han posibilitado que el libro suture un margen en el debate académico sobre la dominación y por el cual, dicho sea de paso, vale la pena revisarlo. Todos los autores del libro están preocupados por el giro intelectual que en los últimos años han tenido las discusiones sobre los estados nacionales. Después de la espesa crítica hacia el enfoque que miraba al Estado como una entidad homogénea y completamente institucional, un giro cultural comenzó a comprender el Estado como una serie de ensambles que, a pesar de su declarada articulación, crearon la imagen de un Estado amorfo cuya representación tenía mucho eco con el "fin de las ideologías". Al mismo tiempo que esto sucedía, los estudios revisionistas de la historiografía latinoamericana se mostraron muy interesados por una revisión crítica de los procesos de hegemonía estatal y crisis de las alternativas político/ideológicas que habían terminado por fracasar en sus intentos de transformación social. Pero a pesar del renovado impulso crítico de esa historiografía, el tópico del Estado fue ocupando un espacio secundario en las discusiones sobre los procesos de dominación y legitimidad de los regímenes políticos latinoamericanos. Las reformas estructurales implementadas por el Estado neoliberal, las regresiones autoritarias, las movilizaciones populares y la violencia que se generó alrededor de estos procesos, volvieron a colocar en la agenda académica el interés por las transformaciones neoliberales de los estados. Algunos grupos académicos se interesaron por rediscutir el Estado bajo una clara influencia foucaultiana del biopoder y la gubermentalidad. La dominación meticulosa de los estados y la "securitización" de nuestros espacios familiares comenzó a pensarse en términos más íntimos, casi como una especie de

El Colegio de Michoacán A.C. México

maldonado_salvador@hotmail.com 
crítica existencial hacia el Estado. Pero, otra vez, volvió a quedar fragmentada la discusión de por qué los estados nacionales se han convertido en los principales generadores de las violencias e ilegalidades.

Obviamente, el tiempo y las ideas estaban cambiando de manera notable, lo que derivó en nuevos planteamientos teóricos y, sobre todo, en una revisión meticulosa de lo que el poder político estaba haciendo con la vida de las personas. En el caso de América Latina, grupos intelectuales se mostraron interesados ya no tanto por las transiciones políticas en sí y por sus fracasos para instaurar regímenes democráticos, sino por el papel que estaban asumiendo los estados nacionales en cuanto a la violencia y la población civil afectada por ella. La violencia social y criminal, en medio de regímenes formalmente democráticos, nos trajo otra vez de vuelta a pensar en el Estado nacional. Varios estudios estaban apareciendo en el transcurso de la primera década del siglo XXI, poniendo atención muy seria en la manera en que se construyen procesos de gubernamentalidad nacional y transnacional, en donde las figuras de la persona y el cuerpo (género y sexualidad) son los principales objetos del biopoder o la "necropolítica" (Mbembe, 2003). Otras orientaciones antropológicas y sociológicas se dirigían a lo que Harvey (2004) ha llamado procesos de "acumulación por desposesión".

Es en este debate intelectual que se sitúa el libro Formas reales de la dominación del Estado, el cual se integra en una nueva preocupación por comprender los efectos de la objetivación del Estado en prácticas, representaciones y discursos de poder. El resultado es la suturación de un margen en los discursos hegemónicos de la "buena gobernanza", que varios académicos de países desarrollados brindaron como remedio para aquellas sociedades de "anacrónica" estatalidad limitada y de supuesta falta de innovación intelectual. Pero la intrépida crítica que los coordinadores y algunos autores del libro reseñado realizan a dicho debate no queda ahí. Con sagacidad intelectual y un cierto tono de ironía, el libro se lanza contra la postura dominante $\mathrm{y}$, por momentos, arrogante, de ciertas disciplinas que se han apropiado del discurso político de la gobernanza, con la esperanza de hablarle al oído al poder a costa de desprestigiar la producción de conocimiento de otras disciplinas. Tal es el caso, por ejemplo, de algunas críticas que recibieron los propios coordinadores del libro por parte de "intelectuales del Norte", según los cuales el tema del Estado estaba "muy trillado" o "ya estaba todo dicho" con respecto al mismo, haciendo eco de posiciones eurocéntricas acerca de la producción de "innovaciones intelectuales" únicamente por los centros metropolitanos. De manera particular, en la introducción al libro se resalta una crítica poderosa a una perspectiva de análisis que observa los problemas de los llamados estados débiles, con democracias fallidas y economías emergentes, bajo una "renovada teoría de la modernización de la guerra fría" (p. 27), en donde los problemas de las sociedades alejadas de los centros metropolitanos no se resolverán aun consolidando sus emergentes estados, sino a partir de gobiernos indirectos promovidos y sostenidos por agencias internacionales con lógicas de mercado. Tanto en la introducción y algunos capítulos como en las conclusiones de este libro colectivo, hay un conjunto de elementos poderosos para elaborar una crítica creativa de las implicaciones teóricas y políticas asumidas por enfoques etnocéntricos sobre el Estado, que terminan por naturalizar la dominación y traducir la responsabilidad del "fracaso" de la ciudadanía para tener sociedades seguras y democráticas.

En medio de este debate subyace una preocupación más teórica, por parte de los autores, que la de señalar simplemente las debilidades y el silencio de discursos 
hegemónicos cuando se refieren a las llamadas sociedades del tercer mundo. Cuando los coordinadores y los colaboradores plantean la necesidad de superar enfoques reduccionistas del Estado, de "politizar" la construcción cultural del mismo, y dejar de verlo como una estructura amorfa, ellos están proponiendo "traer al Estado de regreso", pero sin cosificarlo, para comprender su formación constante en procesos históricos o contingentes. Volver a pensar el Estado sin dejar fuera la gente y observarlo "donde normalmente se declara su inexistencia". ¿Qué es lo que está en el fondo del planteamiento del libro? La originalidad reside en el planteamiento de un enfoque de análisis multisituado de los procesos de construcción del Estado, con énfasis en dimensiones translocales pero al mismo tiempo lo suficientemente ancladas a la espacialidad. Un proceso de análisis similar al propuesto por Abrams (1988) cuando habla sobre "el ejercicio de legitimación". La tarea más significativa que varios autores del libro emprendieron con sus trabajos de investigación etnográfica, sociológica y politológica, es focalizar sus análisis desde la retícula de los márgenes construidos alrededor de los estados nacionales. El concepto de margen se convierte en un desafío conceptual para elaborar análisis profundos de la "densidad" de modos de regulación social; la legibilidad del Estado, la producción de seguridad, etc. El margen es, pues, un concepto central en la obra, porque permite escapar de dualismos y atomizaciones y ver la dominación y la legitimidad de un orden social como un proceso incesante de construcción y redefinición. ¿Qué significan, por tanto, esas formas reales de dominación? Lo que están planteando los autores es un análisis minucioso de las prácticas, discursos y espacios en los que el "Estado" está presente y en donde supuestamente deja de estarlo. Por tanto, el volumen encierra el desafío de volver a traer al Estado de regreso pero con la salvedad de no representarlo como un cuerpo político unificado, sino como un campo social en el que una multiplicidad de actores locales y globales, con poderes diferenciales, compiten por construir proyectos e instaurar formas de dominación bajo discursos de estatalidad.

Casi todos los capítulos tratan de alguna manera la forma en que se construyen las conexiones entre la llamada sociedad y el Estado. Tanto si vemos el trabajo sobre medidas y pesos del sistema métrico estatal, como el trabajo sobre el papel de la Coordinadora Nacional de Trabajadores de la Educación (CNTE) en Oaxaca y los dilemas de su democratización, o bien el trabajo sobre el "paternalismo ecológico", así como el de las vicisitudes de la seguridad; todos ellos están cruzados por un campo social en el que actores concretos sirven de mediación, conflicto o como figuras sobre las que se reproduce una idea de Estado. Siguiendo la "lógica" de conexión de estos diferentes actores políticos con el "Estado" en forma de gobierno, aparato administrativo, etc., lo que me parece fundamental es que se rompe con viejas interpretaciones de verticalismo, cuando los actores de un campo político juegan un doble o triple papel. Al respecto, como señala Agudo en la introducción, se trata a la vez de la expresión material de la dominación y de los medios a través de los cuales se reproduce la idea de un Estado fuerte. Este planteamiento retoma parte de la obra de Nuitjen (2003) para acercarnos a una nueva manera de cuestionar los nodos o redes en que se reproducen formas de dominación. ¿Cómo comprender las mediaciones en el marco de procesos de gubernamentalidad? La dimensión sistémica de las relaciones ambiguas entre "Estado" y "Sociedad" nos obliga a no reducir ni aislar sus procesos de comunicación en formas dicotómicas, sino a tener en cuenta las dimensiones espaciales y temporales en que se rehacen sus relaciones cambiantes, tal como Estrada menciona en las conclusiones del volumen. 
Un tema que deriva de este punto es que en casi todos los capítulos, a la vez que encontramos trazados varios procesos de objetivación material del Estado, observamos también que en los procesos de mediación hay un conjunto de actores que se mueven bajo lógicas que podríamos llamar un tanto tradicionales, en el sentido de los viejos esquemas de comprensión del verticalismo estatal. Es decir, varios estudios de caso muestran que las formas reales de dominación siguen ejerciéndose con cierto cinismo político y por medio del uso de la fuerza y la violencia para imponer determinados intereses. Estas formas reales de dominación, que me parece una aportación central del libro, habían quedado subsumidas en estudios culturalistas sobre discursos y representaciones.

Las transformaciones que los estados nacionales están experimentando siguen siendo tareas pendientes para una agenda de investigación de largo plazo. Todavía no logramos comprender muchas cosas de la naturaleza del nuevo orden social que se construye con las reformas estructurales de tipo neoliberal y sus formas de legitimidad social o violencia contra ellas. Lo cierto es que los esquemas de mediación social entre el "Estado" y la "sociedad" han cambiado profundamente. Además de comprender esta dicotomía como un recurso de poder en sí misma, el llamado tercer sector está ocupando espacios muy importantes que anteriormente podían detentar otros actores sociales. Los procesos de mediación política están cada vez más desplazados por nuevas formas de conexión en las que organizaciones de participación comunitaria u ONG sirven como nuevos espacios de ampliación y profundización del Estado, bajo discursos de "adelgazamiento". Un nuevo paradigma de la arquitectura de los estados pasa ahora por la participación ciudadana como un mecanismo o tecnología de poder en los procesos de gubernamentalidad, pero con consecuencias desastrosas para la población. Tanto los nuevos procesos de mediación como las figuras de un Estado adelgazado están contribuyendo a crear márgenes cada vez más amplios y sobre los cuales, paradójicamente, hay regulaciones excesivas bajo declaraciones de que el Estado no existe o hace falta su presencia. Me parece que, si algo nos hizo considerar nuevamente la importancia de reflexionar sobre esos tipos de espacios "vacíos", fue la violencia que desde hace más de una década está causando grandes transformaciones sociales, políticas y culturales en poblaciones situadas en fronteras difusas. A nivel teórico, fue fundamental la influencia de Michel Foucault en investigaciones sobre la transformación de la noción de persona e individuo en estados criminales o de terror, para usar la frase de un libro recomendable de Aretxaga y Zulaika (2005).

Para terminar, la invitación de los coordinadores del libro a repensar el Estado y sus formas reales de dominación en los márgenes, hace eco de otras preocupaciones como la que representan autores tales como Agamben, donde la discusión central, me parece, es la manera en que se ha transformado la noción de individuo y sus derechos en el marco de aquellas "vidas indignas de ser vividas pero cuya eliminación no compete al Estado" (2006: 174). Es decir, cómo comprender procesos de legitimación y sus efectos de poder en términos de estrategias de militarización, estados de excepción, criminalización social, etc. Me parece que este eje puede darnos una reflexión interesante de la naturaleza de los cada vez más numerosos estados criminales, que no fallidos. Otro eje de reflexión que podría ser útil para seguir pensando en formas reales de dominación consiste en que, como decían los historiadores revisionistas, estamos volviendo a dejar de lado la historia; una historia que trata del conflicto pero que está siendo relegada a una especie de "museificación" de las atrocidades en forma de memoria nacional. Tal como sugiere Abrams (1988), la única forma 
que tenemos de poder diferenciar la idea de Estado del Sistema-Estado es el proceso histórico, que nos hace sensibles a la idea de que no hay máscara detrás de la práctica política; hay que comprender sus modos, efectos y variaciones.

\section{Referencias bibliográficas}

Arams, Philip (1988). "Notes on the difficulty of studying the state". Journal of Historical Sociology, 1 (1): 58-89.

Agamben, Giorgio (2006). Homo Sacer. Valencia, España: Editorial Pre-textos

Aretxaga, Begoña; Zulaika, Joseba (2005). States of Terror. Reno: Center for Basque Studies, University of Nevada.

Corrigan, Philip; Ramsay, Harvie; Sayer, Derek (1980). "The State as a Relation of Production", en P. Corrigan (ed.), Capitalism, State Formation and Marxist Theory. Londres: Quartet Books, 1-125.

Harvey, David (2004). El nuevo imperialismo: acumulación por desposesión. Internet: http://investigacion.politicas.unam.mx/teoriasociologicaparatodos/pdf/Tradici\%F3n/Har vey,\%20David\%20\%20El\%20nuevo\%20imperialismo\%20Acumulaci\%F3n\%20por\%20 desposesi\%F3n.pdf

Mbembe, Achille (2003). "Necropolitics". Public Culture, 15 (1): 11-40.

Nuitjen, Monique (2003). Power, Community and the State. The Political Anthropology of Organization in Mexico. Londres: Pluto Press. 